\title{
Bronchodilator response to salbutamol after chronic dosing with salmeterol or placebo
}

\author{
S.J. Langley, C.M. Masterson, E.P. Batty, A. Woodcock
}

Bronchodilator response to salbutamol after chronic dosing with salmeterol or placebo. S.J. Langley, C.M. Masterson, E.P. Batty, A. Woodcock. CERS Journals Ltd 1998.

ABSTRACT: It has been hypothesized that regular inhaled $\beta_{2}$-agonist therapy causes desensitization of $\beta_{2}$-receptors. The aim of this study was to define whether $\beta_{2}$-receptor desensitization occurs after treatment with the long-acting $\beta_{2}$-agonist salmeterol, assessed by measuring the bronchodilator response to cumulative repeated doses of inhaled salbutamol before and after treatment.

Forty nine stable adult patients with asthma were randomized to receive either salmeterol $50 \mu \mathrm{g}$ b.d. or placebo b.d. from an Accuhaler ${ }^{\circledR}$ for 4 weeks after an initial 2 week run-in period without $\beta_{2}$-agonists. All patients were receiving inhaled corticosteroids. Bronchodilator responsiveness to cumulative repeated doses of inhaled salbutamol were measured before and 12 and $36 \mathrm{~h}$ after the last dose of study treatment. The primary efficacy endpoint was the peak forced expiratory volume in one second (FEV1) response before and after treatment.

There were no significant differences between the two treatment groups in the absolute peak FEV1 or maximal peak expiratory flow (PEF) results 12 or $36 \mathrm{~h}$ after the last dose of study treatment. Significantly higher clinic lung function and diary card parameters were noted in the salmeterol group when compared to the placebotreated patients, demonstrating the beneficial effects of regular salmeterol.

Regular salmeterol usage did not lead to reduced efficacy of usual or higher than usual doses of salbutamol.

Eur Respir J 1998; 11: 1081-1085.

Inhaled $\beta_{2}$-agonists have become the treatment of choice in acute asthma because of their excellent bronchodilating effects $[1,2]$. In recent years however, the regular use of short-acting inhaled $\beta_{2}$-agonists for the treatment of asthma has been controversial, with reports of worsening of asthma control, a desensitization of $\beta_{2}$-receptors and rebound increases in bronchial hyperresponsiveness [3, 4].

The introduction of long-acting $\beta_{2}$-agonists such as salmeterol, which has a bronchodilator action in excess of $12 \mathrm{~h}[2,5]$, has increased the controversy. It has been suggested that prolonged receptor occupancy by these long-acting agonists might increase the likelihood of $\beta_{2}$ receptor down regulation and subsensitivity compared to their short-acting counterparts [3]. Since the publication of SEARS et al. [3] in 1990, attempts have been made to address the question of whether regular inhaled $\beta_{2}$-agonist therapy does lead to desensitization of $\beta_{2}$-receptors, and if so, what the clinical implications are. The results from such studies have been conflicting. Published data have shown that there is no loss of peak flow improvement over periods of 1-12 months [6, 7] with regular use of salmeterol. Treatment ranging from 2 weeks to 12 months with salmeterol $50 \mu \mathrm{g} \mathrm{b.d}$. has also demonstrated that responsiveness to inhaled salbutamol was not decreased during or after treatment, suggesting no change in $\beta_{2}$-receptor sensitivity [8, 9]

Other published data have, conversely, reported that 4 weeks of treatment with the long-acting $\beta_{2}$-agonist for-
North West Lung Research Centre, Wythenshawe Hospital, Manchester, UK

Correspondence: A Woodcock

North West Lung Centre

Wythenshawe Hospital

Southmoor Road

Manchester, M23 9LT

UK

Fax: 441612912243

Keywords: beta-adrenergic receptor sensitivity

salmeterol

bronchodilator

salbutamol dose response curve

Received: July 281997

Accepted after revision January 201998 moterol, results in tolerance to its acute bronchodilator effects [10] and a recently published study has claimed that continuous exposure to salmeterol $50 \mu \mathrm{g} b$.d. results in reduced bronchodilator response to repeated doses of inhaled salbutamol [11]. The authors hypothesized that patients receiving regular treatment with salmeterol might require higher doses of salbutamol for relief of acute bronchoconstriction.

At present, there is no consensus as to whether regular treatment with long-acting $\beta_{2}$-agonists results in $\beta_{2}$-receptor desensitization. This placebo-controlled study, in adults with asthma, was undertaken to evaluate the bronchodilator responsiveness to cumulative repeated doses of inhaled salbutamol after regular exposure to twice daily inhaled salmeterol over 4 weeks.

\section{Patients and methods}

The study was a single-centre, double-blind, randomized, parallel-group study performed at the North West Lung Research Centre in Manchester, UK.

Adult asthmatic patients aged 16-70 yrs with a documented history of mild-to-moderate reversible airways obstruction who required $400-1,000 \mu \mathrm{g} \cdot$ day $^{-1}$ inhaled corticosteroid, such as beclomethasone dipropionate or budesonide or $200-500 \mu \mathrm{g}$ inhaled fluticasone propionate, were included. Patients had to be able to use the Accuhaler ${ }^{\circledR}$ 
(Allen and Hanburys, Uxbridge, Middlesex, UK) correctly and have a forced expiratory volume in one second (FEV1) of 50-90\% of the predicted value. Patients also had to demonstrate a reversibility in FEV1 of at least $15 \%$ following inhalation of salbutamol, having ensured bronchodilator was withheld prior to the clinic visit.

Patients were excluded if they had unstable asthma and had been hospitalized or received oral, depot or parenteral corticosteroids in the preceding 4 weeks, or had suffered a respiratory tract infection in the preceding 4 weeks. Patients were also excluded if they had a known hypersensitivity to inhaled steroids, had received salmeterol in the 2 weeks prior to the study or were smokers of $>20$ cigarettes $\cdot$ day $^{-1}$ and had a smoking history of $>20$ pack-years.

Eligible patients entered a 2 week run-in period during which they were issued with ipratropium to use on an as required basis. Patients were not permitted to take oral xanthines, short-acting or long-acting $\beta_{2}$-agonists or oral/ parenteral corticosteroids during the study period. Urine samples were taken before each dose-response curve to assay for the presence of salbutamol to check patient compliance for this requirement, and the dose counter on the Accuhaler ${ }^{\circledR}$ was used to assess compliance with study treatment. Patients were given a mini-Wright peak flow meter to take home for recording of morning and evening peak expiratory flow (PEF) (best of three blows) on a daily record card (DRC). Symptoms of asthma and the use of rescue ipratropium were also recorded on the DRC.

After a 2 week run-in period, patients returned to the clinic after having withheld their ipratropium for $8 \mathrm{~h}$. Patients were randomized to receive study medication if they had completed the DRC satisfactorily and had taken ipratropium on at least 4 of the last 7 days of the run-in period at a dose $<240 \mu \mathrm{g} \cdot$ day $^{-1}$.

\section{Dose response curves}

A salbutamol dose response curve was performed in eligible patients at Visit 2 using a Sensor Medics Vmax20 spirometer (Yorbalinda, CA, USA). FEV1, forced expiratory flow at $25-75 \%$ of vital capacity (FEF25-75\%) and PEF were measured three times, prior to and $15 \mathrm{~min}$ after salbutamol inhalation, with the best value being recorded. Cumulative doubling doses of salbutamol (delivered from a metered dose inhaler and Volumatic ${ }^{\circledR}$, Allen and Hanburys) were used, starting with a dose of $200 \mu \mathrm{g}$ increasing to $3,200 \mu \mathrm{g}$. This salbutamol dose response curve was repeated 12 and $36 \mathrm{~h}$ after the last dose of study medication.

\section{Study medication}

Eligible patients were randomized to receive either salmeterol $50 \mu \mathrm{g}$ b.d. or placebo b.d. administered by the Accuhaler® for a 4 week treatment period. Patients were instructed to take one puff from the study inhaler each morning and evening.

\section{Study design}

Patients attended the clinic on six scheduled occasions during the study: a screening visit (Visit 1); a randomization visit at the end of the 2 week run-in period (Visit 2); two visits at 2 week intervals (Visits 3,4); a visit $36 \mathrm{~h}$ after the last dose of study medication (Visit 5); and an optional 1 week follow-up visit (Visit 6). Visit 4 was scheduled at least $12 \mathrm{~h}$ after the last dose of study medication. Lung function was measured at each clinic visit.

The study was approved by the local ethics committee and written informed consent was obtained from each patient before their participation in the study.

\section{Analysis}

All analyses were performed on the intent-to-treat population. Patients who had data from at least 1 day of the run-in and treatment periods were included. Data obtained from previous studies showed an estimated standard deviation of peak FEV1 of $0.25 \mathrm{~L}$. To detect a difference between the two treatments of $0.2 \mathrm{~L}$ with $80 \%$ power when tested at the 5\% significance level it was calculated that a total of 48 patients was required.

The primary efficacy variable, peak FEV1, was the maximum FEV1 value measured in each patient during the cumulative salbutamol dose-response curve, irrespective of the dose used. For clinic visit lung function measurements, the changes in peak FEV1, FEF25-75 and PEF from Visit 2 to Visits 3 and 4 were determined using analysis of covariance with terms for treatment and baseline included in the model. Data from the diary card was analysed at Visit 4 only. The PEF was analysed by covariance analysis using terms for baseline and treatment in the model. For all other diary card variables, the Wilcoxon rank sum test was used to assess the differences between treatment groups in the change from baseline (Visit 2) to Visit 4.

Adverse events were summarized by treatment group and compared using the chi-square test.

\section{Results}

A total of 67 patients entered the study of whom 49 were randomized to receive treatment. The main reasons for withdrawal before randomization were failure to fulfil the entry criteria and failure to return to the clinic. Two patients were withdrawn following randomization, one in each treatment group.

The treatment groups were well matched with respect to their demographic data except for age, with the salmeterol group having a higher median age (table 1).

\section{Salbutamol dose response}

Analysis of the primary efficacy variable, the peak FEV1 recorded during the salbutamol dose response, irrespective

Table 1. - Patient demographic characteristics

\begin{tabular}{lcc}
\hline & Salmeterol & Placebo \\
\hline Patients randomized $\mathrm{n}$ & 25 & 24 \\
Sex M/F & $13 / 12$ & $12 / 12$ \\
Age yrs & $49(19-68)$ & $37.5(20-69)$ \\
Baseline FEV1 L·s ${ }^{-1}$ & $2.29 \pm 0.54$ & $2.4 \pm 0.64$ \\
FEV1 \% pred & $73.9 \pm 10.6$ & $73.4 \pm 11.3$ \\
\hline
\end{tabular}

Values are presented as absolute number, median (range) or mean士SEM. M: males; F: females; FEV1: forced expiratory volume in one second; $\%$ pred: percentage predicted. 
of dose, showed that there was no significant difference between the changes in peak FEV1 after 4 weeks treatment and $36 \mathrm{~h}$ after the last dose of study medication in both treatment groups when compared to baseline (table 2 ). In addition, there was no between-group difference in the change in peak dose from pretreatment levels at either visit ( $p=0.088$ and $p=0.067$, respectively).

There was also no significant difference between the change in peak PEF in the two treatment groups at either visit following treatment (table 2 ).

The FEV1 results for the cumulative salbutamol dose response are shown in figure 1 and the PEF results in figure 2. The FEV1 results prior to the start of treatment (Visit 2), at the end of 4 weeks of treatment and $36 \mathrm{~h}$ after the end of treatment are shown. There was a small nonsignificant difference in FEV1 between the treatment groups before the start of treatment, (salmeterol 2.29 $\pm 0.54 \mathrm{~L}$; placebo $2.4 \pm 0.64 \mathrm{~L}$ ) which was taken into account during the analysis, with the Visit 2 data being included as a covariate in the statistical analysis.

Baseline FEV1 at Visit 3 (after 2 weeks of treatment) showed a significantly greater improvement in the salmeterol group $(\mathrm{p}=0.039)$ when compared to values at Visit 2 (pretreatment). This did not reach significance after 4 weeks of treatment $(p=0.55)$. The PEF was also significantly different between the two treatment groups after 2 weeks of treatment $(p=0.012)$, but did not reach significance after 4 weeks of treatment $(\mathrm{p}=0.65)$.

\section{Diary card data}

Diary card data in the salmeterol-treated group showed a significant increase in mean morning and evening PEF after 4 weeks of treatment when compared to the placebo group (table 3). A difference in mean morning PEF of $32.7 \pm 6.8 \mathrm{~L} \cdot \mathrm{min}^{-1}$ was observed between the salmeterol and placebo groups, with both groups having a similar pretreatment baseline value $(\mathrm{p}=0.0001)$ (table 3$)$. Other diary card variables, including daytime symptom scores and percentage symptom-free days, were significantly lower in the salmeterol-treated patients when compared to placebo. At baseline the daytime symptom score was 1 in both groups, which decreased to 0 in the salmeterol group and increased to 1.5 in the placebo group $(\mathrm{p}=0.004)$. The per-

Table 2. - Salbutamol dose response: peak forced expiratory volume in one second $\left(\mathrm{FEV}_{1}\right)$ and peak expiratory flow (PEF)

\begin{tabular}{lcclcc}
\hline & \multicolumn{2}{c}{ Peak FEV1 L } & & \multicolumn{2}{c}{ Peak PEF $\mathrm{L} \cdot \mathrm{s}^{-1}$} \\
\cline { 2 - 3 } \cline { 5 - 6 } & Visit 4 & Visit 5 & & Visit 4 & Visit 5 \\
\hline Salmeterol & $3.01 \pm 0.05$ & $2.98 \pm 0.04$ & & $7.47 \pm 0.13$ & $7.61 \pm 0.13$ \\
Placebo & $3.05 \pm 0.05$ & $3.04 \pm 0.04$ & & $7.64 \pm 0.13$ & $7.63 \pm 0.14$ \\
Difference & 0.04 & 0.06 & & 0.16 & 0.02 \\
p-value & 0.572 & 0.298 & & 0.387 & 0.902
\end{tabular}

Values are presented as mean \pm SEM, adjusted for baseline. The pvalues were calculated using analysis of covariance using Visit 2 data as baseline. Visit 4 was performed $12 \mathrm{~h}$ after the last dose of study medication and Visit $536 \mathrm{~h}$ after the last dose of study medication. centage of symptom free days increased from a baseline value of $30.3 \%$ to $69.4 \%$ in the salmeterol-treated group, compared to $19.8 \%$ and $29.4 \%$, respectively in the placebo-treated group $(\mathrm{p}=0.002)$. Differences were also noted in the night-time scores which did not quite reach significance. Similarly, the median daytime usage of ipratropium was also reduced in the salmeterol group when compared to placebo, although this did not reach significance.
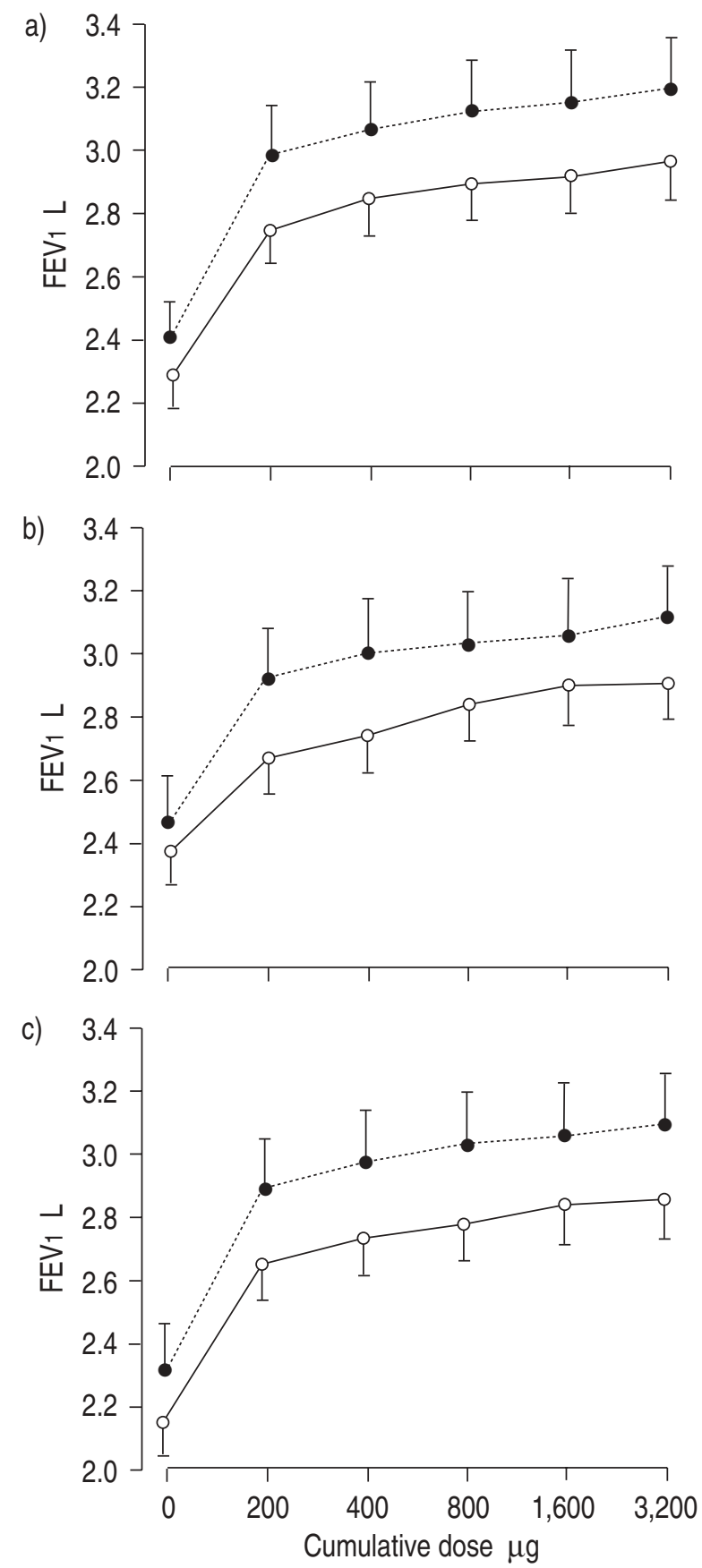

Fig. 1. - Salbutamol dose response, measuring forced expiratory volume in one second (FEV1): a) before treatment with either salmeterol $50 \mu \mathrm{g}$ b.d. or placebo for 4 weeks; b) after 4 weeks of treatment; and c) $36 \mathrm{~h}$ after the end of treatment. Values are presented as mean \pm SEM. $-\mathrm{O}-$ : salmeterol; $\bullet . . .$. : placebo. 
Safety

There were no serious adverse events reported in either treatment group during treatment. The incidence of nonserious adverse events was similar between the two groups. Fifty six per cent of patients reported an event during the treatment period in the salmeterol-treated group, compared to $50 \%$ in the placebo group. The most commonly reported events were headache and rhinitis, with a similar incidence between the groups
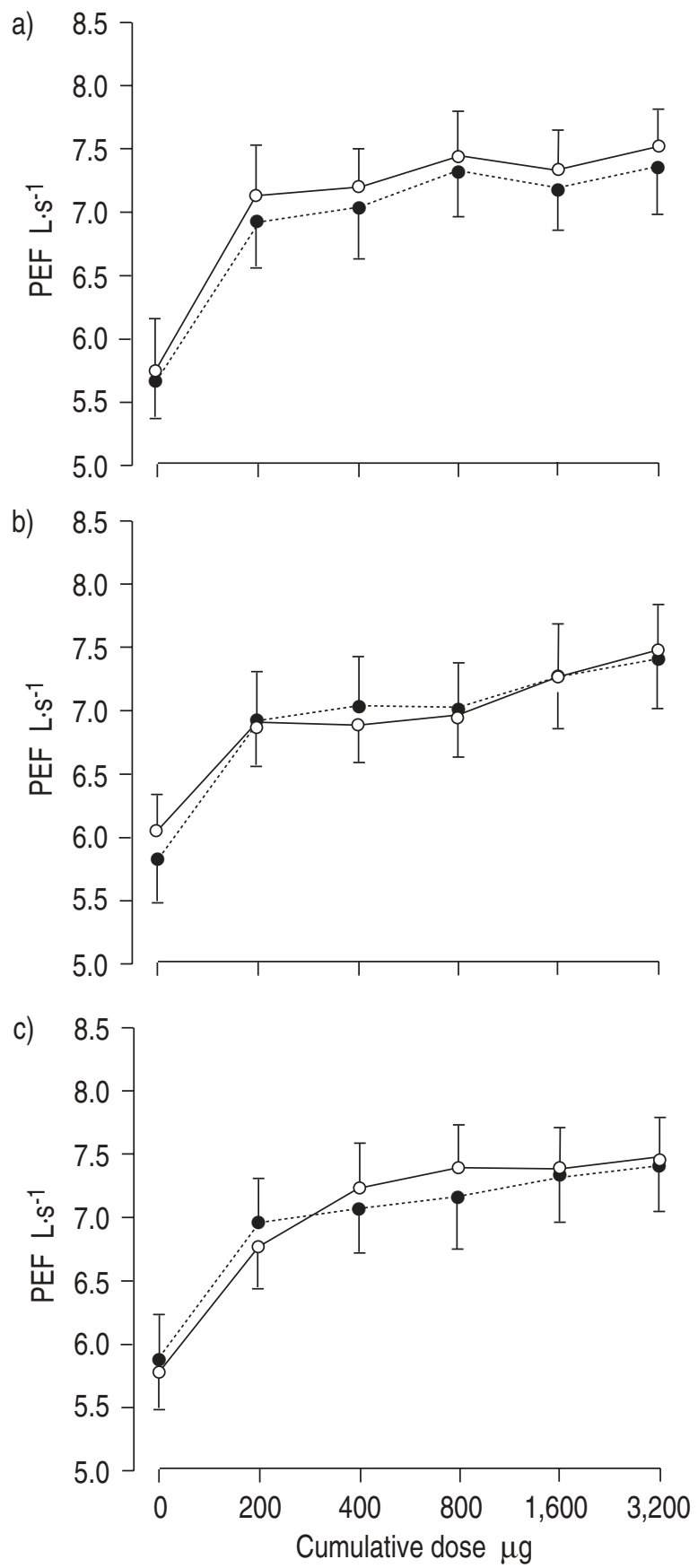

Fig. 2. - Salbutamol dose response, measuring peak expiratory flow (PEF): a) before treatment with either salmeterol $50 \mu \mathrm{g} \mathrm{b.d.} \mathrm{or} \mathrm{placebo} \mathrm{for}$ 4 weeks; b) after 4 weeks of treatment; and c) $36 \mathrm{~h}$ after the end of treatment. Values are presented as mean \pm SEM. $-\mathrm{O}-$ : salmeterol; ...... placebo.
Table 3. - Diary card measurements of peak expiratory flow (PEF)

\begin{tabular}{lccccc}
\hline & \multicolumn{2}{c}{ Morning PEF L·min-1 } & & \multicolumn{2}{c}{ Evening PEF L·min } \\
\cline { 2 - 3 } \cline { 5 - 5 } & Visit 2 & Visit 4 & & Visit 2 & Visit 4 \\
\hline Salmeterol & $368 \pm 70$ & $395 \pm 70$ & & $381 \pm 72$ & $407 \pm 74$ \\
Placebo & $370 \pm 90$ & $361 \pm 84$ & & $390 \pm 93$ & $381 \pm 98$ \\
Difference & & 32.7 & & 30.9 \\
p-value & & 0.0001 & & 0.0003 \\
\hline
\end{tabular}

Values are presented as mean \pm SEM, adjusted for baseline. Difference between the treatment means and the p-values at Visit 4 were calculated using analysis of covariance. Visit 2 was the baseline value. Visit 4 data was collected at the end of 4 weeks of treatment.

\section{Discussion}

In this study, patients receiving salmeterol $(50 \mu \mathrm{g}$ b.d.) for 4 weeks showed a reduction in asthma symptoms (diary card daytime scores) and an improvement in peak flow measurements, manifested by an increase of $>30$ $\mathrm{L} \cdot \mathrm{min}^{-1}$ in the mean morning values when compared to the placebo-treated group. In addition, there was no change in the salbutamol dose-response relationship after chronic dosing with salmeterol.

These results are in keeping with those obtained from two previous studies $[8,9]$, both of which also showed no change in salbutamol response after chronic treatment with salmeterol. However, both of these were open studies with no control group. In one of the studies [8], salmeterol treatment lasted just 2 weeks, whilst in the other [9], the duration of treatment was 12 months. In both of these studies, patients continued using short acting $\beta_{2}$-agonists as rescue medication. The design of the present study was similar to that used by GROVE and LIPWORTH [11], in that a 2 week run-in period without $\beta_{2}$-agonists was used, all patients were receiving inhaled corticosteroids and patients received treatment for 4 weeks. The present study differed in two important respects: 1) a parallel group design was used instead of a crossover study; and 2) the subjects were moderate rather than severe asthmatics. The average (SEM) FEV1 values at randomization for the present study were 73.9 (10.63)\% pred and 73.4 (11.3)\% pred for the salmeterol and placebo groups, respectively, whilst in the study of GROvE and LIPWORTH [11] the mean value at randomization for the whole group was 64 (2.7)\%. Finally, in the present study the maximum dose of concomitant in-haled steroid was $1,000 \mu \mathrm{g}$ of beclomethasone as opposed to $2,400 \mu \mathrm{g}$.

The results of the two studies are very similar, but interpretation is different. Grove and LIPWORTH [11] expressed the results of the dose-response curves as the $\delta$ response. This method of interpreting the results has since been criticized [12-14]. We have expressed our results as absolute values of lung function rather than the change from baseline as, clinically, the former are more relevant for the patient, i.e. the value of lung function (or alternatively the percentage of their personal best) that they achieve at each dose of salbutamol on the dose response curve. In this study we demonstrated no significant difference between treatment groups for the peak (or the gradient) of the dose response curves using analysis of covariance (allowing for baseline adjustments). Re-analysis of the data of GROVE and LIPWORTH [11] using absolute values also shows no change in salb- 
utamol response after salmeterol and in particular the peak FEV1 achieved with salbutamol is unaltered after salmeterol treatment.

One way in which the results of the two studies do appear to differ is the shape of the dose-response curves. After 4 weeks of treatment with either salmeterol or placebo, over $50 \%$ of the improvement in both FEV1 and PEF following salbutamol was achieved after the first dose $(200 \mu \mathrm{g})$, and a plateau of bronchodilation was achieved in both patient groups. This is in contrast to the study of Grove and LipWorTh [11] where, despite a dose of $3,200 \mu \mathrm{g}$, a plateau was not reached with either FEV1 or PEF in either treatment group. This may, in some way, reflect the different patient groups included in the two studies, as alluded to above. It might, therefore, be argued that in this study any degree of subsensitivity may have been missed, as the steep part of the dose-response curve was achieved with a single dose. More information may have been gained if we had started with doses of 25,50 and $100 \mu \mathrm{g}$ salbutamol, to explore the lower parts of the curve. However, in practical terms, doses of 25 and $50 \mu \mathrm{g}$ are not commercially available, and it is reassuring that most of a patient's bronchodilation can be achieved with quite modest doses of rescue $\beta_{2}$-agonist.

Although this and other studies have failed to show tolerance to the bronchodilator response (to either salmeterol itself or salbutamol) following long-term use of salmeterol, there appears to be more evidence suggesting that tolerance to the antibronchoconstrictor effects of salmeterol does occur after chronic use. Previous studies have demonstrated a loss of protection against methacholine $[15,16]$ and exercise [17], but interestingly, not to adenosine monophosphate (AMP) [18], another indirect constrictor agent. However, loss of bronchoprotection to AMP is seen with short acting $\beta_{2}$-agonists [19]. Furthermore, the tolerance that occurs to the effect of methacholine is not prevented by inhaled corticosteroids [20,21]

These findings, along with the results from the present study suggest that different mechanisms are involved for the tachyphylaxis that occurs to bronchodilator and bronchoconsctrictor protector effects of $\beta_{2}$-receptors. The exact reasons remain unclear, although it has been suggested that the $\beta_{2}$-receptors situated on mast cells are more resistant to the effects of tolerance than those in smooth muscle cells, which may give rise to the apparent difference in clinical effect.

Further studies may help to clarify the difference in tolerance seen with bronchodilator and the protection against bronchoconstrictor agents. Furthermore, studying subpopulations with different polymorphisms of $\beta_{2}$-receptors [22], may demonstrate a differential phenotypic response. However, in conclusion, we found no evidence of a desensitization of $\beta_{2}$-receptors (manifested as a reduced bronchodilator response to repeat doses of salbutamol) following 4 weeks treatment of patients with mild/moderate asthma with inhaled salmeterol.

\section{References}

1. Johnson M. The pharmacology of salmeterol. Lung 1990; 168 (Suppl.): 115-119.

2. Ullman A, Hedner J, Svedmyr N. Inhaled salmeterol and salbutamol in asthmatic patients, an evaluation of asthma symptoms and the possible development of tachyphylaxis. Am Rev Respir Dis 1990; 142: 571-575.
3. Sears MR, Taylor DR, Print CG, et al. Regular inhaled beta-agonist treatment in bronchial asthma. Lancet 1990; 336: 1391-1396

4. Vathenen AS, Higgins BG, Knox AJ, Britton JR, Tattersfield AK. Rebound increase in bronchial responsiveness after treatment with inhaled terbutaline. Lancet 1988; 1 : 554-557.

5. Ullman A, Svedmyr N. Salmeterol, a new long acting inhaled beta-2-adrenoceptor agonist. A comparison with salbutamol. Thorax 1988; 43: 674-678.

6. Faurschou P. Chronic dose-ranging studies with salmeterol. Eur Respir Rev 1991; 1: 282-287.

7. Arledge TE, Liddle R, Stahl E, Rossing TH. Salmeterol does not cause tolerance during long-term asthma therapy. J Allergy Clin Immunol 1996; 98: 1116-1119.

8. Ullman A, Hedner J, Svedmyr N. Inhaled salmeterol and salbutamol in asthmatic patients. An evaluation of asthma symptoms and the possible development of tachyphylaxis. Am Rev Respir Dis 1990; 142: 571-575.

9. Lotvall J, Lunde H, Ullman A, Tornqvist H, Svedmyr N. Twelve months, treatment with inhaled salmeterol in asthmatic patients. Effects on $\beta_{2}$-receptor function and inflammatory cells. Allergy 1992; 47: 477-483.

10. Newnham DM, Grove A, McDevitt DG, Lipworth BJ. Subsensitivity of bronchodilator and systemic $\beta_{2}$-adrenoceptor responses after regular twice daily treatment with eformoterol dry powder in asthmatic patients. Thorax 1995; 50: 497-504.

11. Grove A, Lipworth BJ. Bronchodilator subsensitivity to salbutamol after twice daily salmeterol in asthmatic patients. Lancet 1995; 346: 201-206.

12. $\mathrm{Ng}$ HW. Bronchodilation subsensitivity to salbutamol after salmeterol (Letter). Lancet 1995; 346: 968.

13. Barnes N. Bronchodilatation subsensitivity to salbutamol after salmeterol (Letter) Lancet 1995; 346: 968.

14. Weinberger M. Bronchodilatation subsensitivity to salbutamol after salmeterol (Letter). Lancet 1995; 346: 968.

15. Booth H, Bish R, Walters J, Whitehead F, Walters EH. Salmeterol tachyphylaxis in steroid treated asthmatic subjects. Thorax 1996; 51: 1100-1104.

16. Cheung D, Timmers MC, Zwinderman, AH Bel, EH, Dijkman JH, Sterk PJ. Long-term effects of a long acting $\beta_{2}$-adrenoceptor agonist, salmeterol on airway hyperresponsiveness in patients with mild asthma. $N$ Engl $J$ Med 1992; 327: 1198-1203.

17. Ramage L, Lipworth BJ, Ingram CG, et al. Reduced protection against exercise induced bronchoconstriction after chronic dosing with salmeterol. Respir Med 1994; 88: 363-368.

18. Yates DH, Worsdell M, Barnes PJ. Effect of regular salmeterol treatment on albuterol-induced bronchoprotection in mild asthma. Am J Respir Crit Care Med 1997; 156: 988-991.

19. O'Connor BJ, Aikman S, Barnes PJ. Tolerance to the non-bronchodilator effects of inhaled beta- 2 agonists in asthma. N Engl J Med 1992; 327: 1204-1208.

20. Kalra S, Swystun VA, Bhagat R, Cockcroft DW. Inhaled corticosteroids do not prevent the development of tolerance to the bronchoprotective effect of salmeterol. Chest 1996; 109: 953-956.

21. Yates DH, Kharitonov SA, Barnes PJ. An inhaled glucocorticoid does not prevent tolerance to the bronchoprotective effect of a long acting inhaled $\beta_{2}$-agonist. $A m \mathrm{~J}$ Respir Crit Care Med 1996; 154: 1603-1607.

22. Green SA, Turki J, Hall IP, Liggett SB. Implications of genetic variability of human $\beta_{2}$-adrenergic receptor structure. Pulm Pharmacol 1995; 8: 1-10. 